\title{
Correction to: Communication Competencies and International Graduates' Employability Outcomes: Strategies to Navigate the Host Labour Market
}

\section{Thanh Pham ${ }^{1}$}

Published online: 14 August 2021

(c) Springer Nature B.V. 2021

\section{Correction to: Journal of International Migration and Integration https://doi.org/10.1007/s12134-021-00869-3}

The original version of the article unfortunately contained these fine errors:

1. Page 4, last paragraph of 'Diverse Perspectives on International Graduates' Employability and Communication Competencies' section, there is an unnecessary blank line added between Items 1 and 2 . The list should be presented as below:

1. What limitations...

2. How can...

3. How do...

2. Page 6, last paragraph of 'Theoretical Framework' section, there are three places where 'author' should be replaced by the real references. They should be presented as below:

1. Most recently, Pham (2020) and ...

The reference of this citation is: Pham, T. (2020). Reconceptualise employability of returnees: What really matters and strategic navigating approaches. Higher education. DOI: 10.1007/s10734-020-00614-2

2. Most recently, Pham (2020) and Pham and Jackson (2020) developed the concept of ...

The original article can be found online at https://doi.org/10.1007/s12134-021-00869-3

Thanh Pham

thanh.t.pham@monash.edu

1 Faculty of Education, Monash University, 19 Ancora Imparo Way, Clayton, VIC, Australia 
The reference of this citation is: Pham, T., \& Jackson, D. (2020). Employability and determinants of employment outcomes. In N. Tran, T. Pham, M. Tomlinson, K. Medica, \& C. Thompson (Eds.), Developing and utilizing employability capitals: Graduates' strategies across labour markets (pp. 237-255). Netherlands: Routledge.

3. Pham and Jackson (2020) evidenced that international graduates ...

The reference of this citation is: Pham, T., \& Jackson, D. (2020). Employability and determinants of employment outcomes. In N. Tran, T. Pham, M. Tomlinson, K. Medica, \& C. Thompson (Eds.), Developing and utilizing employability capitals: Graduates' strategies across labour markets (pp. 237-255). Netherlands: Routledge.

3. Page 9, at the end of the first excerpt in the section 'Enhancing Expected Communication Competencies as a Navigation Strategy' there should be '-pseudonyms'. The excerpt should look like below:

I tried to learn authentic language on social media like Facebook and LinkedIn because they suited daily conversations more, and I could speak like Aussies [Australians] ... Imagine I have been here for six years and it is a 'must' for me to work on at least my English. (Jay - pseudonyms)

4. Page 12, at the beginning of 'Going Beyond Structural Barriers as a Navigation Strategy' section, there is unnecessary broken line.

These lines should be continuously connected like this:

Hoa experienced a dilemma that Rizvi (2009, p. 261) described as people finding themselves being pulled between ...

5. Page 14, the last paragraph under 'Discussion and Conclusion', Author should be replaced by a real reference.

It should look like this:

Some used friend networks to find work in their ethnic community but then felt bored and attempted to enter the mainstream workforce. Pham (2021) emphasised that graduate employability should be seen ...

The reference of this citation is: Pham, T. (2021). Reconceptualise graduate employability: the role of 'capitals' in navigating the teaching profession. In $\mathrm{T}$. Pham \& B. Soltani, Enhancing student education transitions and employability: From theory to practice (pp. 123-136). United Kingdom: Routledge.

The original article has been corrected.

Publisher's Note Springer Nature remains neutral with regard to jurisdictional claims in published maps and institutional affiliations. 